\title{
DE LA JUSTICIA CLIMÁTICA A LA JUSTICIA ECOLÓGICA: LOS DERECHOS \\ DE LA NATURALEZA
}

\section{FROM CLIMATE JUSTICE TO ECOLOGICAL JUSTICE: THE RIGHTS OF NATURE}

\author{
Teresa Vicente Gimenez \\ Profesora Titular de Filosofía del Derecho \\ Universidad de Murcia \\ teresavi@um.es
}

Fecha de recepción: 1 de junio de 2020 / Fecha de aceptación: 1 de septiembre de 2020

RESUMEN: El presente trabajo trata de poner de manifiesto la importancia de la realización del nuevo paradigma de la Justicia Ecológica, junto a las nuevas teorías de la justicia en curso como la Justica Climática y la Justicia Ambiental, para proteger la naturaleza y enfrentar la crisis climática y ambiental. En la Era del Antropoceno, se hace imperativo elaborar una teoría de la Justicia Ecológica para poder proteger jurídicamente a la naturaleza por sí misma, a partir del reconocimiento del valor de los ecosistemas para ser una entidad jurídica sujeto de derechos. Siendo indispensable para ello partir de una nueva ética capaz de enraizar la Justicia y la Ecología: la Ética Ecológica. Lo que permitirá dotar a la Politica y al Derecho de los procedimientos y de los procesos jurisdiccionales ambientales adecuados, para lograr una protección más efectiva de la naturaleza, como sujeto de derechos. En este artículo se analizan dos casos donde, respectivamente, la Ley y la Jurisprudencia declaran la personalidad juridical de entidades naturales, como los Rios, y les otorgan derechos en base a su propio valor. Se trata del caso del Río Atrato por la Corte Constitucional de Colombia y del Río Whanganui por el Parlamento de Nueva 
Zelanda. Para concluir reconociendo que el cambio jurídico que enfrenta el nuevo modelo de la Justicia ecológica y los derechos de la naturaleza implica, necesariamente, la transición del modelo del Estado de Derecho moderno y el concepto tradicional de la ciudadanía, hacia una nueva ciudadanía ecológica, que no sólo incluye los derechos humanos sociales y ecológicos, sino también los derechos propios de la naturaleza.

RESUM: El present treball tracta de posar de manifest la importància de la realització d'el nou paradigma de la Justícia Ecològica, al costat de les noves teories de la justícia en curs de la Justica climàtica i la Justícia Ambiental, per protegir la naturalesa i enfrontar la crisi climàtica i ambiental en l'era de l'antropocè. Es fa imperatiu elaborar una teoria de la Justícia Ecològica, per poder protegir jurídicament a la naturalesa per si mateixa, a partir d'el reconeixement del valor dels ecosistemes per ser una entitat jurídica subjecte de drets. Sent indispensable per a això partir d'una nova ètica capaç d'arrelar la justícia i l'ecologia: l'ètica ecològica. El que permetrà, des del nou paradigma de la Justícia ecològica, dotar la Política i a el Dret dels procediments i els processos jurisdiccionals ambientals necessaris per a aconseguir una protecció de la natura com a subjecte de drets. L'article s'analitzen dos casos on la llei i la Jurisprudència declaren la personalitat juridical a entitats naturals, com els Rios, i li atorguen drets en base al seu propi valor. Es tracta, respectivament, de el cas de el Riu Atrato per la Cort Constitucional de Colòmbia i de el Riu Whanganui pel Parlament de Nova Zelanda. Per concloure reconeixent el canvi jurídic que enfronta el nou model de Justícia ecològica i els drets de la natura implica necessàriament la transició de el model de l'Estat de Dret modern i el concepte tradicional de la ciutadania, cap a una nova ciutadania ecològica, que no només inclou els drets humans socials i ecològics, sinó també els drets propis de la natura.

ABSTRACT: The present work endeavours to show the full foundation of the realization of the new paradigm of Ecological Justice, beyond the new theories of Climate Justice and Environmental Justice, to protect nature and to face the current climate and environmental crisis in theAnthropocene Era. It is imperative to develop a theory of Ecological Justice, in order to legally protect nature by itself, based on the recognition of the value of ecosystems to be a legal entity subject to rights. In this respect, it is indispensable a new ethics capable of rooting justice and ecology: 
ecological ethics. Therefore, the new paradigm of ecological Justice provides Policy and Law with the environmental procedures and jurisdictional processes necessary to achieve more effective protection of nature as a subject of rights. Two cases will be studied where Law and Jurisprudence recognize nature as a subject of law. These are, respectively, the case of the Atrato River by the Colombian Constitutional Court and the Whanganui River by the New Zealand Parliament. To conclude, recognition this is the advance from human rights to the rights of nature, as the foundation of the proposal for an ecological Rule of Law for the 21st century, which implies the transition from the nineteenth-century model of the modern Rule of Law, and the traditional concept of citizenship, towards a new ecological citizenship, which includes not only social and ecological human rights, but also the rights of nature.

PALABRAS CLAVE: Justicia ecológica - Justicia climática - era del antropoceno visión ecocéntrica - visión biocéntrica - derechos bioculturales - ciudadanía ecológica - derechos de la naturaleza - Estado Ecológico de Derecho.

PARAULES CLAU: Justícia ecològica - Justícia climática - era de l'antropocè - visió ecocéntrica - visió biocèntrica - drets bioculturals - ciutadania ecològica - drets de la natura - Estat Ecològic de Dret.

KEY WORDS: Ecological Justice - Climate Justice - Anthropocene era - ecocentric vision - biocentric vision - biocultural rights - ecological citizenship - rights of nature Ecological State of Law.

SUMARIO: I. Introducción. II. Del antropocentrismo al ecocentrismo: la realización del nuevo paradigma de la justicia ecológica. III. Colombia, Chocó, Río Atrato: la Corte Constitucional de Colombia reconoce al Río Atrato como sujeto de derecho. 1. Sentencia de la Corte Constitucional, Bogotá, D.D., 10 de noviembre de 2016. a) El Estado Social de Derecho en la Constitución de 1991. b) La Constitución Ecológica, la relevancia constitucional del medio ambiente y la biodiversidad: los derechos bioculturales y la protección de los ríos, los bosques y las fuentes de alimento. c) La Constitución Cultural, el derecho a la supervivencia física, cultural, y espiritual de las comunidades étnicas: los derechos territoriales y culturales. d) El principio de prevención y el principio de precaución. e) Reconocer al Río Atrato, su Cuenca y afluentes como una entidad sujeto de derechos: tutoría o representación legal, los guardianes y el equipo asesor. 2. Análisis doctrinal de la Sentencia Constitucional desde la perspectiva del nuevo paradigma de la Justicia ecológica. IV. Nueva Zelanda, Río Whanganui: el Parlamento aprueba la Ley que declara persona jurídica al Río Whanganui. 1. La Ley Te Awa Tupua, Acta de reconocimiento del Río Whanganui como sujeto de derecho, de 20 de 
marzo de 2017. a) Te Awa Tupua, es el conjunto indivisible y vivo del Río Whanganui y tiene todos los derechos y deberes de una persona jurídica. b) Te Pou Tupua, el tutor o representante legal del río. c) los derechos y responsabilidades en relación al uso y la ocupación del Río Whanganui. d) La Ley obliga a la Corona. 2. Análisis doctrinal de la Ley Te Awa Tupua desde la perspectiva del nuevo paradigma de la Justicia ecológica. V. Conclusiones.

\section{INTRODUCCIÓN}

Si observamos la historia de la evolución ética de la humanidad, como Aldo Leopold en la Ética de la Tierra (1949), cada etapa que desarrolla la dimension ética muestra un progreso en la comprensión de la humanidad respecto a su lugar en el mundo: desde las relaciones del ser humano consigo mismo a las relaciones con la familia, la tribu, hasta las relaciones entre la humanidad en su conjunto. Y, finalmente, las relaciones con el medio natural. En esta evolución ética se pasa de concebir al ser humano como amo y propietario de su medio a concebirlo como miembro de una comunidad biótica o ecosistema. En este mismo sentido, Darwin (1874) observa la historia moral del ser humano y la describe como una continua extensión de su objeto, desde lo individual a lo social y, finalmente, hacia el mundo animal. Se trata del avance desde la relación entre los seres humanos a la relación entre la especie humana y las demás especies que integran la naturaleza. La ampliación de la dimensión de la ética al medio natural, hasta ahora limitada al ámbito de lo humano, tiene como resultado el nuevo paradigma de la ética ecológica.

En el siglo veinte se desarrolla la ciencia de la ecología que muestra las interrelaciones entre el ser humano y el medio ambiente, la integridad del dato ecológico se expresa en el concepto de ecosistema, como categoría primaria y esencial de la nueva ciencia (Margalef, 1974). El uso del término ecología se inicia a finales del siglo XIX con el zoólogo alemán Ernst Haeckel (1870), y a lo largo del siglo XX se consolida y florece en el ámbito cientítico-académico, apareciendo en España las primeras cátedras de ecología en los años 80 del siglo pasado, con el profesor Ramón Margalef en la Universidad de Barcelona, el profesor Fernando González Bernáldez en la Universidad Autónoma de Madrid, y el profesor Luis Rámirez en la Universidad de Murcia. 
A comienzos del nuevo milenio, el impacto de la actividad humana sobre el sistema Tierra enfrenta a la humanidad al cambio global, y la sitúa en una nueva era geológica conocida como Antropoceno, la cual pone de manifiesto la contradicción de un planeta degradado y enfermo, basado en un modelo de desarrollo que permite la explotación ilimitada de sus recursos. La amenaza de la crisis climática y ecológica actual, constatada en los últimos informes del Panel Intergubernamental de Expertos sobre Cambio Climatico (IPCC, 2018) y sobre Biodiversidad y Servicios de Ecosistemas (IPBES, 2019), demuestra que el modelo de Desarrollo actual sigue contaminando el aire, el agua y el suelo. Después de todo, es la humanidad la que ha acelerado las tasas de extinción en 1,000 veces, y es la actividad humana la fuerza impulsora de la extinción masiva actualmente en curso, "una amenaza para la biodiversidad igual al poder destructivo del asteroide Chicxulub que aniquiló el 70 por ciento de las especies hace 65 millones de años" (Wilson, 2016). La destrucción humana y la extinción ecológica masiva de nuestra época hacen que el tema de la consideración ética de la ecología sea aún más acuciante, lo que incluye, por ejemplo, intereses y derechos.

En sentido paralelo a la evolución ética y la evolución científica, expuesta en los párrafos anteriores, la historia de la evolución del Derecho moderno muestra un avance en la inclusión de nuevos sujetos al ámbito jurídico, como las mujeres, los niños, todas las razas, y las diferentes clases sociales (siglo XX) que pasan a ser reconocidas como personas juridicas. A comienzos del siglo XXI la lógica de esta evolución nos lleva a considerar la naturaleza como un sujeto legal, sin embargo la inclusión de la naturaleza como sujeto de derecho plantea enormes discusiones doctrinales y dificultades en el ámbito juridico y require de una revisión ontológica y epistemológica de la teoría del derecho tradicional.

El camino hacia el reconocimiento jurídico de los derechos de la naturaleza, basada en la conciencia ecológica, la ética ecológica y la justicia ecológica, nos sitúa en una nueva vision ecocéntrica de la vida, que permite comprender, conjuntamente, la realidad de la amenza que sufre nuestro planeta y la humanidad. Desde esta nueva visión integradora de la vida, se trata de dar respuesta a una de las grandes contradicciones con las que la humanidad se encuentra en el siglo XXI: los límites de un modelo de crecimiento ilimitado en un planeta con recursos limitados. 
Ante la dificultad actual que plantea otorgar el estatus de persona jurídica a la naturaleza, esto es, designar a las entidades naturales como sujetos jurídicos, conviene recordar que en el inicio del Derecho moderno, por primera vez en la historia del Derecho, se reconoce que las entidades mercantiles tienen sus propios derechos, como las personas y ciudadanos.

La novedosa adición a la literatura jurídica actual que aporta el presente trabajo consiste en mostrar el avance del nuevo modelo de Justicia Ecológica, que limplica el abandono del antropocentrismo, en que el que se ha basado la fórmula del Estado de derecho o Derecho moderno hasta nuestros días, que sólo reconoce al ser humano como sujeto de derecho, y a la naturaleza la considera como un objeto para su explotación ilimitada. En efecto, la visión antropocentrica concibe al ser humano como única razón de ser del sistema legal y a los recursos naturales como simples objetos al sevicio del primero. La vision biocéntrica, como paso intermedio, concibe las relaciones entre la humanidad y la naturaleza, lo que va a posibilitar el salto hacia una nueva concepción ecocéntrica. Esta visión biocéntrica es compartida por los tres modelos de la Justicia: Justicia ambiental, Justicia climática y Justicia ecológica, y reivindica concepciones más globales y de apoyo de la responsabilidad humana medioambiental, y defiende los deberes de la humanidad con respecto a las generaciones futuras. El modelo de Justicia ecológica incorpora una visión ecocéntrica, que concibe la naturaleza como un verdadero sujeto de derechos, y reconoce a los seres humanos como partes integrales del ecosistema global, la biosfera.

A pesar del triunfo actual del modelo antropocéntrico, en los últimos años ha surgido en el orden jurídico, tanto por la vía de la Ley como de la Jurisprudencia, el reconocimiento de las relaciones inseparables entre los seres humanos y el medio natural, y en considerar a la naturaleza como una entidad viva sujeto de derechos. Por la vía de la Jurisprudencia, este es el caso de la Sentencia del Tribunal Constitucional de Colombia y el Río Atrato. Por la vía de la Ley aprobada en el Parlamento, este es el caso de la Ley de Te Awa Tupua, el Río Whanganui, aprobada el día 20 de marzo por el Parlamento de Nueva Zelanda. En ambos se otorga a las entidades medioambientales, como los ríos, el reconocimiento de sujeto jurídico con su propios derechos, lo que genera derechos y obligaciones de protección y restauración. 
La estructura en cada uno de los casos objeto de estudio en este trabajo es la misma: en primer lugar se aborda un estudio riguroso y auténtico, es decir, basado en el análisis del texto legal, sin aportaciones pesonales ni doctrinales. $Y$ en un segundo momento, se estudia la novedad científica que implican tales resoluciones jurídicas, desde el paradigma del justicia ecológica, y se aporta doctrina y literatura jurídica en relación a cada caso concreto.

\section{DEL ANTROPOCENTRISMO AL ECOCENTRISMO: LA REALIZACIÓN DEL NUEVO PARADIGMA DE LA JUSTICIA ECOLÓGICA.}

La realizacion de la Justicia ecológica obliga a una revision ontológica y epistemológica en el ámbito del Derecho: pasar de la concepción antropocéntrica del Derecho (el ámbito del orden jurídico son los seres humanos) a una concepción ecocéntrica (amplía el ámbito jurídico para incluir al ecosistema, del cual forma parte el ser humano). Previamente, pasar de la concepción antropocentrica rígida a una concepción antropocéntrica más suave y flexible, conduce a la concepción biocéntrica, la cual amplia y corrige los límites de la concepción antropocéntrica clásica. Este paso intermedio permite, finalmente, dar el salto hacia una nueva concepción ecocéntrica del Derecho.

1- A comienzos del siglo $X X I$, se ha dado un gran paso hacia la visión biocéntrica con el reconocimiento de la relación entre la Naturaleza y el Derecho, por la vía específica de las Resoluciones de las Naciones Unidas. En 2005 la Comisión de Derechos Humanos de las Naciones Unidas adoptó la Resolución 2005/60, sobre los derechos humanos y el medio ambiente como parte del Desarrollo Sostenible. Y cuatro años después, el Consejo de Derechos Humanos de las Naciones Unidas adoptó la Resolución 10/4 de 25 de marzo de 2009 sobre derechos humanos y cambio climático, donde se require a la Oficina del Alto Comisionado de las Naciones Unidas para los Derechos Humanos para que procure información sobre el cambio climático y los derechos humanos, y se da la bienvenida a la decisión de nombrar un Relator Especial para que informe regularmente sobre los impactos que provoca el calentamiento global en los derechos humanos. El 3 de junio de 2008 la Asamblea General en el marco de la Organización de Estados Americanos (OEA) aprobó la Resolución sobre derechos humanos y cambio climático en las Américas, AG/RES 
2429 (XXXVIII-O/08), e invoca en dicha Resolución la realización de estudios explorativos para la creación de leyes y cuerpos jurisdiccionales.

La nueva perspectiva jurídica, que afirma la relación entre los derechos humanos y el medio ambiente, permite incluir la protección del medio natural dentro del ámbito de protección de los derechos humanos, por ser la causa de la violación de tales derechos, como el derecho a la vida, a la alimentación, a la salud, al agua, a la vivienda, al territorio, a la cultura, a la espiritualidad y a la autodeterminación, entre otros. Se trata de la materialización de la Justicia Ambiental, esto es, de su renocimiento efectivo en el ámbito del Derecho. La Justicia Ambiental se basa en los problemas medioambientales como la contaminación, la biodiversidad, la desertificación, la desforestación, los residuos, etc., y como afecta a las personas, en el desarrollo del Derecho ambiental, y en los enfoques de la Jurisprudencia ambiental (Upendra Baxi, 2016).

Un caso pionero en este sentido ha sido la decisión del Tribunal Europeo de Derechos Humanos, de fecha 9 de diciembre de 1994, donde reconoció que los problemas medioambientales (contaminación) afectan a las personas y sus derechos. Se trata del Recurso de Queja presentado por Gregoria López Ostra alegando que el Estado español no la había protegido como ciudadana frente a la contaminación causada por una instalación de tratamiento de residuos, y que había violado su derecho al respeto de la vida doméstica, privada y familiar (López Ostra vs. España. Solicitud №. 16798/90). El Tribunal Europeo consideró la relación entre el derecho a un medio ambiente sano y el derecho al respeto de la vida privada, el hogar y la vida familiar, declarando la responsabilidad estatal por acciones de compañías privadas en su jurisdicción, y dictaminó que "la contaminación ambiental severa puede afectar el bienestar de las personas y evitar que disfruten de sus hogares de tal manera que afecten negativamente su vida privada y familiar".

2- A partir de 2015 con el Acuerdo del Clima de París y la Cumbre de las Naciones Unidas donde se establecen los Objetivos de Desarrollo Sostenible de la Agenda 2020-2030, la Justicia climática (vision biocéntrica) cobra protagonismo en la esfera jurídica. Aunque es cuestionable la medida en que el Acuerdo sobre el Clima de París refleja de hecho la Justicia climática, ya que las revelaciones sobre el cambio 
climático que se recogen en los informes posteriores a 2015 demuestran que la situación está empeorando y se ha vuelto crítica.

La Justicia climática, como desarrollo de la visión biocéntrica, constata el hecho de que la crisis climática no afecta ni afectará a todo el mundo por igual. En muchos casos, los más afectados por el cambio climático son los menos responsables de las emisiones de gases de efecto invernadero que están causando la crisis climática actual, y estas desiguladades que genera el cambio climático repercuten en la justicia global. Como afirma Tin Marshall (2016), los prisioneros de la geografía miran el pasado, el presente y el futuro para ofrecer una visión esencial de uno de los principales factores que determina la historia del mundo.

El marco normativo que proporciona el Acuerdo de París de 2015 y la Agenda de Desarrollo sostenible 2030 de las Naciones Unidas impulsan una necesaria "Acción Climática", para la realización del nuevo modelo de Justicia Climática, creando obligaciones para los gobiernos y entidades privadas. En este sentido, los Estados han de desarrollar los instrumentos efectivos para combatir las causas y los efectos del calentamiento global, esto es, están obligados a llevar a cabo políticas de adaptación y mitigación al cambio climático, sin embargo, estas medidas de adaptación y mitigación se realizan por los gobiernos de los países de manera lenta, y continuamente son paralizados ante la incertidumbre y las certezas inalcanzables.

La Cumbre sobre el Clima COP21 en París, donde se adoptó el Acuerdo climático de no exceder un aumento de 2.0ำ comenzando con el período de la Revolución preindustrial (1750), fue presidida por Ségolèn Royal, quien en su Manifiesto por una Justicia ecológica (2017) declara la necesaria acción climática mundial, y destaca a tres mujeres que han impulsado la conciencia y la acción ecológica: Rachel Carson, la bióloga marina y escritora impulsora de la conciencia ecológica en los años sesenta; Vandana Shiva, la filósofa y activista india impulsora del ecofemismo de los años ochenta; y Wangari Muta Maathai, bióloga, activista, y Premio Nobel de la Paz 2004.

Uno de los principales elementos donde se materializa la Justicia climática son los llamados conflictos climáticos. Las disputas climáticas tienen como objetivo presionar al legislador estatal, la administracción estatal y las entidades privadas a cumplir, a través del poder judicial del Estado, el compromiso mundial de garantizar 
un clima adecuado: con la redución de las emisiones de gases de efecto invernadero, la producción de energía renovable, las medidas legales apropiadas para implementar los principios de precaución y prevención, con el objetivo de prevenir desastres ambientales y promover el principio de desenvolvimiento sustentable (Gabriel Wedy, 2019).

Los litigios climáticos se multiplican, muchos de ellos han sido recopilados en estudios legales, como el de Ottavio Quirico y Mouloud Boumghar, Climate Change and Human Rights (2016). En algunos de estos casos, se pretende hacer responsable al Estado de causar el cambio climático, como en el caso de las dos solicitudes a la Comisión Interamericana de derechos humanos (IA ComHR) por los indígenas del Ártico: la solicitud en 2005 del Consejo de los Innuit del Circulo Polar Ártico contra los Estados Unidos de América por violaciones de derechos humanos resultado del calentamiento global causado por sus actos y omisiones; y la solicitud en 2013 del Consejo de los Athalabaskan por las violaciones de sus derechos humanos debido al calentamiento y el deshielo del Ártico causado por las emisiones de carbón negro del gobierno de Canadá. En otros casos, se pretende hacer responsable a las compañías privadas, como es el caso Kivalina, donde en 2007 el pueblo nativo de Kivalina demandó ante el Tribunal del Distrito de Kivalina, y luego ante el Tribunal Supremo de los Estados Unidos, a diversas compañías eléctricas y de petróleo por contribuir al cambio climático y causar con ello las peores consecuencias del huracán Katrina. En algunos litigios se pretende hacer responsables a Estados y compañías, como en el de Nigeria en 2005, donde Jonah Gbemre en su nombre y en el de la comunidad Iwherekan del Delta de Nigeria presentó una demanda contra la compañía petrolera Shell, la Corporación Petrolera Nacional Nigeriana y el Fiscal-General de Nigeria, por los derrames de petróleo y gases residuales que han provocado daños y degradación del medio ambiente que violan sus derechos humanos fundamentales. Otros casos, siguen la tendencia de proteger el medio natural en base a los derechos humanos de los pueblos indígenas, por ejemplo los indios Yanomami contra el gobierno de Brasil (Resolución 12/85. IAComHR, 5 de marzo de 1985); o el caso de la comunidad indígena Kichwa de Sarayaku contra Ecuador (Resolución Serie C N²45. IACtHR de 27 de junio de 2012). En otros supuestos se protege el medio natural en base a los derechos de las generaciones futuras, como el caso de la Republica de Filipinas 
donde la Corte Suprema de Manila resuelve una demanda interpuesta por los niños (G.R. N¹01083, 30 de julio de 1993).

En todos estos casos, la protección del medio ambiente natural se lleva a cabo en función de la protección de los seres humanos y sus derechos (visión antropocéntrica clásica), aunque ahora se extiende a una nueva perspectiva de la responsabilidad del ser humano hacia la naturaleza (visión biocéntrica, que corrige los límites de la visión antropocéntrica clásica). El paradigma de la justicia climática y la justicia ambiental comprende la transición entre las visiones antropocéntrica y biocéntrica.

3- En los últimos años, la vanguardia jurídica de la Ley y la Jurisprudencia da el salto hacia una concepción ecocéntrica del Derecho: reconocer la protección de la naturaleza en base a sus propios derechos y su valor íntrinseco, otorgando personalidad jurídica a las entidades naturales. A nivel jurisprudencial, la Corte Constitucional de Colombia, Sección Sexta de Revisión, en la sentencia T-622 del 2016, reconoció al río Atrato, su cuenca y sus afluentes el estatus de una entidad sujeto de derecho, como titular de derechos a la protección, conservación, mantenimiento y restauración. En 2017, el Parlamento de Nueva Zelanda reconoció por Ley como sujeto de derechos al río Whanganui. Se trata de la materialización del nuevo paradigma de la Justicia ecológica en el ámbito del Derecho positivo.

El camino hacia el reconocimiento jurídico de los derechos de la naturaleza se inició con la Carta de la Naturaleza de las Naciones Unidas de 1982, la cual estableció que la especie humana es parte de la naturaleza y la vida depende del funcionamiento ininterrumpido de los sistemas naturales. Y se fortaleció con la Carta de la Tierra, una declaración de principios para la defensa de los derechos de la Tierra, de todos los seres que la habitan y de toda forma de vida, la cual no fué admitida en la Cumbre de la Tierra de 1992, pero la fuerza del movimiento popular que la respaldaba logró su reconocimiento por la UNESCO en el año 2000.

La nueva perspectiva de la Justicia ecológica y los derechos de la naturaleza ponen en riesgo el concepto tradicional del Derecho, basado en la separación entre Naturaleza y Cultura, lo que suscita los mayores obstáculos jurídicos y discusiones doctrinales. Sin embargo, la actual crisis climática y ambiental, y la nueva ciencia de la ecología, proporcionan argumentación suficiente para un nuevo modelo de Justicia 
que se sustente en la comprensión del ser humano como parte del ecosistema (Vicente y Ramírez, 1997).

El nuevo modelo de la Justicia ecológica debe tener como eje central el principio de distribución, esto es, que las entidades naturales pasan a formar parte del reparto de lo que a cada cual le corresponde para su desarrollo y en base a su propio valor. El valor de la naturaleza reside en ella misma, en su propia efectividad, que está determinada por su estructura interna y se describe según su durabilidad, productividad y eficiencia. La idea de Justicia ha de asumir la cuestión ecológica porque ahí están los fundamentos materiales y espirituales de las necesidades humanas y ecológicas, lo que a cada cual le pertenece, que incluye los límites que impone el medio natural (Vicente, 2016).

\section{COLOMBIA, RIO ATRATO: LA CORTE CONSTITUTIONAL DE COLOMBIA RECONOCE AL RIO ATRATO COMO UN SUJETO DE DERECHO.}

El río Atrato, que atraviesa la selva tropical del Pacífico noroccidental de Colombia, ha sufrido durante años los estragos de la extracción minera de oro y platino, y la explotación forestal, lo que ha provocado en la actualidad una profunda crisis humanitaria y ambiental.

La Sentencia del Tribunal Constitucional aporta la novedad jurídica de cuestiones legales relevantes, como la de garantizar derechos bioculturales a las comunidades indígenas, y la de asignar al río Atrato personalidad jurídica, con ellas abre una vía legal revolucionaria en la protección de la naturaleza, al amparo de la Justicia ecológica y sobre el presupuesto del fortalecimiento de la Justicia social.

El modelo de la Justicia Ecológica se crea a partir de la Justicia social y los derechos sociales (visión antropocéntrica), que ahora se amplía con los derechos socioecológicos, y los derechos bioculturales (vision biocéntrica). Y sobre este presupuesto del fortalecimiento de la Justicia social, mediante la realización efectiva de los derechos humanos sociales y ecológicos, se construye el nuevo modelo de la Justicia ecológica (vision ecocéntrica) que permite, además, otorgar derechos a la naturaleza. 


\section{Sentencia de la Corte Constitucional de Colombia, Bogotá, D.D., 10 de noviembre de 2016}

La Sala Sexta de Revisión de la Corte Constitucional de la República de Colombia (T-622 de 2016. Expediente: T-5.016.242) dictó Sentencia en Bogotá el diez de noviembre de 2016, en respuesta a la Accion de Tutela interpuesta por el Centro de Estudios para la Justicia Social "Tierra Digna" -en representación del Consejo Comunitario Mayor de la Organización Popular Campesina del Alto Atrato (Cocomopoca), el Consejo Comunitario Mayor de la Asociación Campesina Integral del Atrato (Cocomacia), la Asociación de Consejos Comunitarios del Bajo Atrato (Asocoba), el Foro Inter-étnico Solidaridad Chocó (FISCH) y otros- contra la Presidencia de la República, el Ministerio de Ambiente y Desarrollo Sostenible y otros. Dentro del proceso de revision de fallos proferidos por el Consejo de Estado -Sección Segunda, Subsección A- y el Tribunal Administrativo de Cundinamarca.

El lugar donde se desarrollan los hechos de la Acción de Tutela referida es el departamento del Chocó, que se encuentra en una de las regiones de mayor diversidad natural del planeta conocida como el Chocó biogeográfico, que cubre $187.400 \mathrm{~km}^{2}$. El departamento del Chocó tiene una extensión de $46.530 \mathrm{Km}^{2}$, lo que equivale al $4.07 \%$ del total de la extensión de Colombia, y su organización territorial está conformado por 30 municipios distribuidos en 5 regiones: Atrato, San Juan, Pacífico Norte, Baudo (Pacífico Sur) y Darién. Es un territorio de gran diversidad natural, étnica y cultural donde confluyen multiples grupos raciales, con una población cercana a los 500.000 habitantes, de los cuales el $87 \%$ es afrodescendiente, $10 \%$ indígena y $3 \%$ mestiza. Todas estas comunidades han hecho de la cuenca y las riberas del río Atrato no sólo su territorio, sino también el espacio para reproducir la vida y recrear la cultura.

Los motivos por los que se solicita el amparo constitucional es la grave crisis en materia de salud, socio-ambiental, ecológica y humanitaria que se vive en la Cuenca del río Atrato, sus afluentes y territorios aledaños. En la Acción de Tutela los demandantes solicitan al juez constitucional que se tutelen los derechos fundamentales a la vida, a la salud, al agua, a la seguridad alimentaria, al medio ambiente sano, a la cultura y al territorio de las comunidades étnicas accionantes, y en consecuencia, se emitan las órdenes y medidas oportunas para poder articular 
soluciones estructurales ante la grave crisis ecológica y humanitaria que se padece. También se destaca que se han presentado varias Acciones Populares, sin que con ello se haya logrado articular la acción estatal.

En el trámite de instancia, el Juez Constitucional ordenó notificar la acción de tutela a las entidades demandadas para que pudieran ejercer su derecho a la defensa. La Sala Sexta en Sede de Revision decidió vincular el caso sub examine y solicitar información a varias entidades, y en respuesta se recibieron 26 contestaciones. En base a todo lo anterior, la Sala Sexta de la Corte Constitucional declaró ser competente para dictar Sentencia de Revisión. Y la Sala estimó que la Acción de Tutela era procedente para proteger los derechos fundamentales de las comunidades étnicas, y señaló que concurrían todos los requisitos necesarios para la procedencia de dicha Acción.

Declarada la competencia del Tribunal y la procedencia de la acción judicial, la Sala entró a estudiar el fondo del asunto, donde se analizaron las siguientes cuestiones jurídicas:

a) El desarrollo de la fórmula del Estado Social de Derecho reconocida en la Constitución de 1991.

La Sala consideró que esta fórmula ha sido desarrollada por la jurisprudencia del Tribunal Constitucional a lo largo de 25 años, lo que ha generado toda una revolución de los derechos encaminada hacia la construcción de un genuino Estado social de Derecho. En la tarea de construcción de un Estado social de Derecho genuino, la Sala afirma que esta fórmula responde a los principios fundamentales de una organización social justa que permita dar solución a las necesidades básicas insatisfechas que deben ser atendidas de manera prioritaria, superando así la concepción clásica del Estado de Derecho, en la que el Estado no intervenía en procurar la atención de las necesidades sociales.

En relación con el principio de dignidad humana, la Corte ha establecido que no basta simplemente que la persona exista, es necesario que exista en un marco de condiciones materiales, culturales y espirituales que permitan vivir con dignidad. En su estrecha relación con el principio de solidaridad, la Corte ha entendido en términos generales un acuerdo de mutua ayuda y de responsabilidad compartida para la satisfacción de las necesidades individuales y colectivas. 
Respecto al principio de prevalencia del interés general, la Corte ha señalado que en el estudio de cada caso concreto, para resolver el asunto en cuestión, deben armonizarse y ponderarse los principios constitucionales en tensión teniendo en cuenta el complejo concepto de interés general. Por ultimo, en relación al concepto de bienestar general -que ha venido tomando forma desde comienzos del siglo XX y es directa consecuencia del modelo del "Estado del Bienestar" europeo- exige a la nación y a las entidades territoriales diseñar e incluir la atención especial de estas necesidades dentro de sus planes y presupuestos, que además, deben recibir prioridad sobre cualquier otra asignación en tanto hacen parte de lo que se ha denominado gasto público social.

De esta forma, la jurisprudencia de la Corte Constitucional ha desarrollado ampliamente los postulados normativos del Estado social de Derecho colombiano, en busca de realizar la justicia social, pero en especial, el interés superior en la protección del medio ambiente a través de la denominada "Constitución Ecológica".

b) La Constitución Ecológica, la relevancia constitucional del medio ambiente y la biodiversidad: la protección de los ríos, los bosques y las fuentes de alimento.

En cuanto a la fórmula de la Constitución ecológica, la Sentencia del Alto Tribunal se refiere a las múltiples disposiciones normativas que existen en la Constitución de 1991, que permiten explicar el interés superior de la naturaleza en el ordenamiento jurídico colombiano y la protección especial que se le otorga. Lo que permite, al menos tres aproximaciones teóricas: 1) una vision antropocéntrica, que concibe al ser humano como única razón de ser del sistema legal y a los recursos naturales como simples objetos al sevicio del primero; 2) una visión biocéntrica, que reivindica concepciones más globales y solidarias de la responsabilidad humana, y que abogan por los deberes del hombre con la naturaleza y las generaciones venideras; 3) finalmente, una vision ecocéntrica, que concibe a la naturaleza como un auténtico sujeto de derechos y que respalda cosmovisiones plurales y alternativas a los planteamientos anteriores.

Para la Sala, el enfoque ecocéntrico encuentra pleno fundamento en la Constitución de 1991, el cual entiende la naturaleza y el medio ambiente como existencias merecedoras de protección en sí mismas, y toma conciencia de la interdependencia que nos conecta a todos los seres vivos de la Tierra. En este sentido 
reconoce a los seres humanos como partes integrantes del ecosistema global, antes que a partir de categorías normativas de dominación, simple explotación o utilidad.

Este enfoque integral de protección, que cobra especial relevancia en el constitucionalismo colombiano, permite explorar una visión alternativa de los derechos colectivos de las comunidades étnicas en relación con su entorno natural y cultural, que se han denominado "derechos bioculturales" (biocultural rights). El concepto legal de los derechos bioculturales es una nueva categoría especial que unifica los derechos de las comunidades étnicas a los recursos naturales y a la cultura, entendiéndolos integrados e interrelacionados.

En suma, la Corte afirma en su sentencia que los denominados derechos bioculturales resultan del reconocimiento de la profunda e intrínseca conexión que existe entre la naturaleza y la cultura de las comunidades étnicas e indígenas que lo habitan. El elemento central de este enfoque es la existencia de una vinculación intrínseca entre naturaleza y cultura, entre el ecosistema y la especie humana. $Y$ subraya la importancia de la diversidad biológica y cultural de la nación para las próximas generaciones y la supervivencia del planeta. La visión biocéntrica, que incluye los derechos bioculturales, permitirá a la Corte Constitucional reconocer finalmente, en la resolución del caso, al río Atrato como sujeto de derechos (visión ecocéntrica).

c) La Constitución Cultural, el derecho a la supervivencia física, cultural y espiritual de las comunidades étnicas: los derechos territoriales y culturales.

La Sala Sexta expone en su sentencia las consideraciones sobre lo que el constitucionalismo colombiano ha denominado Constitución Cultural. La Corte explica que la Constitución de 1991 recoge en su articulado el deber del Estado de proteger las riquezas culturales de la Nación y promover y fomenter el acceso a la cultura de todos los ciudadanos; pero no señaló una formula precisa, sino que dejó al legislador o al ejecutivo a cargo de esa reglamentación. Lo que propicia el estudio de la Constitución Cultural. En este sentido, el Tribunal Constitucional señala que la expresión "derechos culturales" designa los derechos humanos incluidos en el campo de los "derechos económicos, sociales y culturales".

Para la Corte está claro que el concepto de Constitución Cultural es parte sustancial de la configuración del Estado social de derecho, al igual que la 
Constitución Ecológica, que conlleva el mandato de proteger la naturaleza. En la protección cultural y ecológica se encuentran incluidas todas las comunidades étnicas colombianas, sus formas de vida, sus costumbres, lenguas y tradiciones ancestrales, así como sus derechos culturales y territoriales y la profunda relación que estas comunidades tienen con la naturaleza. La Corte Constitucional ha reconocido en reiterada jurisprudencia, que los pueblos indígenas, tribales y afrocolombianos tienen un concepto del territorio y de la naturaleza que resulta ajeno a los cánones jurídicos de la cultura occidental: no constituye un objeto de dominio sino un elemento esencial de los ecosistemas y de la biodiversidad con los que interactúan cotidianamente (por ejemplo, ríos y bosques).

Las comunidades y la naturaleza están siendo presuntamente amenazadas por la realización de actividades intensivas de explotación minera con sustancias químicas tóxicas y maquinaria pesada en la Cuenca del río Atrato, afluentes, bosques y territories de comunidades indígenas, lo que de por sí pondría en inminente riesgo no solo su existencia física, la perpetuación y reproducción de las tradiciones y la cultura ancestral, sino el hábitat y los recursos naturales del lugar en donde se construye y se desarrolla la identidad de estas comunidades como grupos étnicos.

d) El Principio de Prevención y el Principio de Precaución en material ambiental y en la salud. La minería y sus efectos sobre el agua, el medio ambiente y las poblaciónes humanas.

La Corte afirma que el Principio de Prevención es un postulado de máxima importancia para el Derecho ambiental, en cuanto significa un cambio de dirección de toda política pública y del marco legal desde un modelo pendiente de la sanción y reparación, hacia un modelo que prepara y organiza las tareas necesarias para evitar que el daño se produzca. Requiere, por ello, de acciones y medidas regulatorias y administrativas que se emprendan en una fase temprana, antes que el daño se produzca o se agrave. Este principio busca que las acciones de los Estados se dirijan a evitar o minimizar los daños ambientales.

La eficacia del Principio de Prevención, la acción preventiva, require de una armonización con el Principio de Precaución, que opera en ausencia de la certeza científica que exige el primero. De este modo, se flexibiliza el rigor del conocimiento necesario para que el Estado tome una decisión, esto es, el absoluto conocimiento 
de las consecuencias que tendrá sobre el medio ambiente el desarrollo de determinado proyecto, obra o actividad.

e) Finalmente, en la Resolución del caso por la Corte Constitucional, la Sala Sexta de Revisión de la Corte Constitucional resuelve:

Declarar la existencia de una grave vulneración de los derechos fundamentales a la vida, al agua, a la seguridad alimentaria, al medio ambiente sano, a la cultura y al territorio de las comunidades étnicas que habitan la Cuenca del río Atrato y sus afluentes. Que dicha vulneración de derechos fundamentales es imputable a las entidades del Estado colombiano accionadas por su conducta omisiva al no proveer una respuesta institucional idónea, articulada, coordinada y efectiva para enfrentar los multiples problemas históricos, socioculturales, ambientales y humanitarios que aquejan a la región y que en los últimos años se han visto agravados por la realización de actividades intensivas de minería ilegal.

Ordenar a las entidades del Estado colombiano que lleven a cabo las medidas oportunas que permitan articular soluciones estructurales ante la grave crisis ecológica y humanitaria que se padece.

Reconocer al Río Atrato, su cuenca y afluentes como una entidad sujeto de derechos a la protección, conservación, mantenimiento y restauración a cargo del Estado y las comunidades étnicas. En consecuencia, la Corte ordenó al Gobierno nacional que ejerza la tutoría y representación legal del río, a través de la institución que el Presidente de la República designe, que bien podría ser el Ministerio de Medio Ambiente, en conjunto con las comunidades étnicas que habitan la Cuenca del río Atrato en Chocó. Adicionalmente, los reprentantes legales del río Atrato deberán diseñar y conformar una comisión de guardianes del río Atrato, integrada por los dos guardianes designados y un equipo asesor al que deberá invitarse al Instituto Humboldt y WWF Colombia.

Otorgar efectos inter comunis a la presente decisión para aquellas comunidades étnicas del Chocó que se encuentren en igual situación fáctica y jurídica que las accionantes. Los efectos inter comunis pueden definirse como aquellos efectos de un fallo de tutela que de manera excepcional se extiende a situaciones concretas de personas que, aún cuando no promovieron el amparo constitucional, se encuentran igualmente afectadas por la situación de hecho o de derecho que lo 
motive, lo que se justifica por la necesidad de dar a todos los miembros de una misma comunidad un trato igualitario que asegure el goce efectivo de sus derechos fundamentales.

\section{Análisis doctrinal de la Sentencia Constitucional desde la perspectiva del nuevo paradigma de la Justicia ecologica.}

Hoy tenemos el deber de reparar y de proteger la naturaleza, porque la degradación del Planeta ha sido desencadenada por la acción humana, y porque tenemos un deber con respecto al futuro de la humanidad. La idea de justicia de "dar a cada cual lo suyo" se amplia ahora al medio natural. La idea de Justicia de dar a la naturaleza lo que le corresponde para su desarrollo significa, en el lenguaje del Derecho positivo, declarar a la naturaleza persona jurídica y otorgarle derechos para su defensa y protección.

La propuesta de dar personalidad jurídica a las entidades naturales fue objeto inicial de reflexión por la teoría jurídica en los años setenta, con el artículo de Christopher D. Stone (1972) Should trees have standing? Towards legal rights for natural objects, donde plantea que la naturaleza puede tener personalidad jurídica y ser titular de derechos, protegidos y defendidos por un tutor o un representante legal, siguiendo la idea llevada a la práctica por el Derecho con anterioridad, al otorgar derechos legales a las corporaciones y a las entidades inanimadas.

Para fortalecer la idea de reconocer y garantizar derechos básicos a la naturaleza se necesita, previamente, desarrollar una nueva ética ecológica, capaz de ampliar las responsabilidades humanas al medio natural. El desarrollo de la ética ecológica, y de la conciencia ecológica, van a permitir la configuración del nuevo modelo de la Justicia ecológica, que trata de dar al ser humano y a los elementos de la naturaleza lo que les corresponde para su realización.

En los años ochenta, la doctrina alemana se preocupa por este tema y la necesidad de un nuevo planteamiento que una la ética y la ecología, como paso previo a la elaboración de un nuevo modelo jurídico basado en la interacción del ser humano con la naturaleza. En este sentido, un trabajo pionero es el del profesor Dieter Birnbacher (University of Essen) Ökologie und Ethik (1980), donde recopila destacados artículos de la doctrina existente. A continuación se expondrán las ideas 
de dos de estos autores, el profesor Spaemann y el professor Tribe, que tratan de resolver dos de los grandes problemas a los que se enfrenta la Teoria de la Justicia: la protección de la naturaleza desde su propio valor, esto es, los derechos de la naturaleza; y los derechos de las generaciones futuras.

El problema de las generaciones futuras es abordado por el professor Robert Spaemann (Universidad de Stuttgart, Heidelberg y München) en su artículo La intervención técnica en la naturaleza como un problema de ética política. El profesor justifica nuestras obligaciones hacia las generaciones futuras en base a la idea de "unanimidad de la especie humana". En este sentido el profesor afirma que si se presupone la especie humana como una unidad integrada y continuada durante el tiempo, como forma natural que integra o incluye tanto futuras como pasadas generaciones, entonces, a los individuos, como componentes de la especie humana, les corresponden derechos jurídicos naturales, que se pueden concretar en derechos fundamentales y humanos, como el derecho a vivir y sobrevivir, incluidas las dimensiones de un medio natural idóneo.

El problema de la protección del medio ambiente en base al valor de la naturaleza en sí es estudidado por Laurence H. Tribe en su artículo ¿Qué argumentos existen en contra de los árboles de plástico? El profesor afirma que los valores intrínsecos e imponderables del medio ambiente pueden ser tenidos en cuenta de la misma forma que los valores económicos y técnicos. Estas afirmaciones sobre el valor de la naturaleza en sí se convierten en afirmaciones sobre el perjuicio por el aprovechamiento (la explotación del hombre). Tribe parte de que los valores del medio natural, que a menudo se describen como cuestionables, no aprehensibles o no medibles, tienen características especiales por las cuales se contraponen a un tratamiento igual con temas tan concretos como el poder técnico y la eficiencia económica. La formulación del problema busca una objetividad difícilmente alcanzable, que lleva a omitir una serie de valores propios de la naturaleza, que se podrían denominar como frágiles, los cuales tienen que ver con personas que aún no existen (generaciones futuras) y valores que tienen que ver no con las personas sino con la naturaleza (los derechos de la naturaleza).

La nueva ética ecológica conlleva una nueva responsabilidad: la responsabilidad de la humanidad hacia la naturaleza. En este sentido Hans Jonas en 
en su trabajo El principio de responsabilidad. Ensayo de una ética para la civilización tecnológica (1995) propone una ética de la responsabilidad que impone "el principio de responsabilidad" para con el medio natural. La responsabilidad ante la representación del mal que le hemos hecho a la naturaleza: "lo paradójico de nuestra situación consiste en que el respeto perdido hemos de recobrarlo a través del estremecimiento".

La realización del nuevo paradigma de la Justicia ecológica en el campo del Derecho aún no se ha desarrollado. Como ya se ha señalado, el modelo de Justicia ecológica tiene como base el modelo de Justicia social, y la formula del Estado social de Derecho, responde a los principios fundamentales de una organización social justa que permita dar solución a las necesidades básicas insatisfechas que deben ser atendidas de manera prioritaria, superando así la concepción clásica del Estado de Derecho, en la que el Estado no intervenía en procurar la atención de las necesidades sociales.

Por ello, el modelo del Estado social del derecho colombiano busca lograr la justicia social, con la implementación de principios sociales y ecológicos, como los principios de justicia social y distributiva, y los principios de prevención y precaución, junto con otros principios fundamentales, como los principios de autonomía territorial, pluralismo y diversidad étnica y cultural de la nación, el principio de la dignidad humana y el principio de prevalencia del interés general. La Sentencia del Alto Tribunal señala que la jurisprudencia constitucional y los instrumentos de derecho internacional que han sido ratificados por Colombia, y otros instrumentos adicionales, han consolidado el desarrollo de un enfoque integral de protección que ha contribuido a amparar tanto la diversidad biológica como la diversidad cultural de la nación. Lo que ha significado un gran avance en el modelo del Estado social de Derecho, que reconoce la protección de los derechos de las comunidades étnicas desde una perspectiva integral, esto es, biocultural.

La transición del Estado social de Derecho al Estado ecológico de Derecho, incluye, como señala Mario Peña Chacón, el fenómeno jurídico de la "ecologización de los derechos humanos" (2018). Para entender esto debe tenerse presente la existencia de una serie de derechos humanos autónomos e independientes entre sí, pero íntimamente ligados al derecho a un ambiente sin riesgos, limpio, saludable y 
sostenible. Los cuales se clasifican en dos grupos: derechos procedimentales y derechos sustantivos, que deben actuar de manera conjunta.

Recientemente, recuerda Chacón, algunos sistemas jurídicos empiezan a reconocer a nivel constitucional, legal y jurisprudencial, los denominados derechos de la naturaleza otorgándole personalidad jurídica propia a diversos ecosistemas, y también los llamados derechos bioculturales. A nivel jurisprudencial, la Corte Constitucional de Colombia, Sección Sexta de Revisión, en la sentencia T-622 del 2016, reconoció al río Atrato, su cuenca y sus afluentes el estatus de una entidad sujeta de derechos a la protección, conservación, mantenimiento y restauración. Esa misma línea siguió la Sala de Casación Civil de la Corte Suprema de Justicia en la sentencia STC-4360 del 2018, al otorgar derechos de la naturaleza a la Amazonía colombiana y con ello, estatus de sujeto de derecho. A la vez, el Tribunal Administrativo de Boyacá, en la sentencia de acción de tutela del 29 de mayo de 2018, otorgó ese mismo estatus al Páramo de Pisba.

El nuevo Estado ecológico de Derecho tiene como presupuestos el modelo de la Justicia ecológica y la nueva ética ecológica planetaria, que obligan a repensar el concepto Justicia en la era geológica del Antropoceno. Como señala Mario Peña Chacón (2019), la Justicia Ecológica del siglo XXI debe ser a la vez: local, regional, nacional, transfronteriza y planetaria; intrageneracional e intergeneracional; e intra especies e inter especies, teniendo como fin, asegurar un espacio operacional seguro para la humanidad y las demás formas de vida. La Justicia Ecológica en el siglo XXI es sinónimo de Justicia para el Planeta.

Fruto del desarrollo histórico del Derecho, los derechos humanos fundamentales ahora se reconocen a nivel mundial, sin embargo, los humanos no pueden existir sin el medio natural. La idea de si deberíamos también otorgar derechos a las entidades ambientales ha ganado fuerza en los últimos años. En este sentido, Nick Mount en su artículo ¿Puede un río tener derechos legales? Visité las selvas de Colombia para descubrirlo (2017). El caso de Colombia es de particular interés para Nick Mount como científico y geógrafo del río, porque el río Atrato fluye a través de un "punto caliente de biodiversidad" mundialmente reconocido, en la selva tropical del Pacífico noroccidental de Colombia. La decisión del Tribunal constitucional de Colombia de reconocer derechos al Río Atrato es sutilmente diferente de las 
demás porque uno de los argumentos legales es centrarse en los "derechos bioculturales", que se refieren a los derechos de las comunidades étnicas en relación con su entorno natural y su cultura.

En el ámbito del Derecho positivo, para garantizar los derechos a la naturaleza se necesita, previamente, reconocer y garantizar a todos los seres humanos los derechos sociales como auténticos derechos subjetivos, como son los derechos de libertad, y no ser considerados como meros principios orientadores a merced de las opciones políticas, como ocurre en el modelo del Estado social occidental conocido como Estado del bienestar. Se trata, en todo caso, de un nuevo modelo posterior al Estado del bienestar, donde se mezclan elementos clásicos del Estado social con elementos más propios de un contexto postsocial. En este sentido Nancy Fraser (2005) habla de un enfoque más allá del Estado del Bienestar, y plantea un nuevo modelo democrático postwestfaliano. Para la autora, la teoría de la justicia democrática postwesfalian nos anima a plantear y a responder a una cuestión clave en nuestro tiempo, que consiste en cómo podemos integrar la mala distribución, la falta de reconocimiento y la falta de representación en un modelo postwestfaliano.

El Estado ecológico de Derecho implica un nuevo concepto de ciudadanía, la ciudadanía ecológica y la ciudadanía planetaria. En relación a la "ciudadanía ecológica", Andrew Dobson (2005) se refiere a la diferencia conceptual entre los términos "ciudadanía ambiental" (justicia ambiental) y "ciudadanía ecológica" (justicia ecológica). Dobson utiliza ciudadanía ambiental en términos de derechos positivos razonables y consensuados, legitimados procedimentalmente y limitados al espacio Estado-nación, que no altera sustancialmente el concepto de ciudadanía. De otro lado, el autor utiliza el término de ciudadanía ecológica para referirse a unos derechos y deberes extracontractuales y universales que se centran en la ciudadanía como virtud, que corresponde a la Justicia, y que nos obliga a repensar las concepciones tradicionales de ciudadanía.

La ciudadanía ecológica supera el concepto tradicional de ciudadanía en el Derecho, al incluir ahora a las futuras generaciones y a los ecosistemas. En todo caso, la dimensión temporal de la justicia es fácil de abordar a partir del modelo tradicional de ciudadanía. En este sentido, Brian Barry (1978) se refiere a un principio de justicia como "la igualdad de oportunidades", que podría satisfacer la nueva dimensión de 
responsabilidad colectiva: cada generación debería disponer de un capital ecológico básico para dar cobertura a las necesidades ecológicas básicas.

En el análisis del concepto sobre "ciudadanía ecológica", es importante distinguir entre conceptos afines. Chris Hilson en su artículo Ciudadanía ecológica republicana en la Encíclica Papal 2015 sobre el medio ambiente y el cambio climático (2018) sitúa el análisis del concepto de "ciudadanía ecológica" en el contexto de la literatura académica sobre el tema, por ejemplo Dobson y Brian, para explicar la distinción particular entre la "ciudadanía ecológica republicana" y la "ciudadanía ambiental liberal".

La ciudadanía ambiental liberal pone el énfasis en los derechos humanos individuales que disfrutan los ciudadanos en relación con el medio ambiente. La libertad que disfrutan los ciudadanos liberales es la libertad negativa de no injerencia de otras personas. La ciudadanía ecológica republicana, en común con otros modelos de ciudadanía ecológica o verde (Dobson, 2003), en lugar de derechos, enfatiza la idea de las obligaciones que los ciudadanos tienen (Barry, 2006). La libertad dirigida a los ciudadanos es la libertad como no dominación. Esto va más allá de la mera no injerencia, reconociendo que una relación en la que una parte ejerce el dominio sobre otra puede significar no injerencia, pero también constituye una restricción a su libertad. Para evitar la exposición al ejercicio del poder arbitrario, la libertad como no dominación requiere mecanismos de rendición de cuentas, es decir, la idea de obligaciones que tienen los ciudadanos.

Hilson afirma que, aunque la Encíclica no se refiere explícitamente a la "ciudadanía ecológica republicana", la visión de ciudadanía ecológica que ofrece tiene mucho en común con la teoría política republicana y la escritura académica sobre el tema en la tradición republicana.

\section{NUEVA ZELANDA, RÍO WHANGANUI: EL PARLAMENTO APRUEBA LA LEY QUE DECLARA PERSONA JURÍDICA AL RÍO WHANGANUI.}

El río Whanganui, Te Awa Tupua para los maoríes, es el tercer río más largo de Nueva Zelanda (Aotearoa) y el primero navegable. Está situado al sur de la Isla 
Norte y discurre durante 290 kilómetros desde una altitude de 600 metros hasta desembocar en el Mar de Tasmania.Te Awa Tupua es un todo indivisible y vivo, que comprende el río Whanganui desde las montañas hasta el mar, incorporando todos sus elementos físicos y metafísicos.

El lecho del Río Whanganui significa el espacio de tierra que cubren las aguas del río Whanganui en su máximo caudal sin sobrepasar sus orillas; e incluye el subsuelo, las plantas unidas al lecho, el espacio ocupado por el agua y el espacio aéreo sobre el agua.

Whanganui Iwi son grupos de ascendencia indígena, que toman su nombre, su espíritu y su fuerza del gran río que fluye desde las montañas de la isla norte central hasta el mar. El grupo político más grande en la sociedad maorí preeuropea fue el iwi (tribu). El Iwi, generalmente consistía en varios hapū relacionados (clanes o grupos de descendencia). El hapū de un iwi a veces podría luchar entre sí, pero se uniría para defender el territorio tribal contra otras tribus. Los hapū, como divisiones nombradas de maoríes iwi (tribus), tienen membresía determinada por descendencia genealógica. Una persona maorí puede pertenecer o tener enlaces a muchos hapū diferentes.

La Ley declara que Te Awa Tupua es una persona legal y establece la oficina de Te Pou Tupua, que será el rostro humano de Te Awa Tupua y actuará en su nombre. En la Ley Te Awa Tupua Whanganui Iwi significa el grupo colectivo que comprende a cada individuo que desciende de una persona que, en cualquier momento posterior al 6 de febero de 1840, ejerció los derechos y responsabilidades consuetudinarios con respecto al río Whanganui.

A partir de la entrada en vigor de la Ley Te Awa Tupua, el Río Whanganui tiene derechos, deberes y responsabilidades jurídicas, y podrá ser representado en un tribunal por un delegado de la Corona y un delegado de la minoría whanganui iwi: Te Pou Tupua.

Aunque desde la perspectiva occidental, la iniciativa del Parlamento de Nueva Zelanda de reconocer al Río Whanganui como persona jurídica es pionera en el ámbito jurídico, para los Whanganui forma parte de su cultura ancestral. La dificultad que plantea reconocer derechos a la naturaleza radica en que el valor e interés propio de las entidades naturales choca con el concepto de derecho subjetivo que se 
encuentra anclado en la cultura occidental. Sin embargo, no es más extraño que en la base del Derecho moderno se otorgue personalidad jurídica a una compañía mercantil, una fundación u otro tipo de asociación. Siguiendo el ejemplo de los Whanganui Iwi este obstáculo solo se plantea con el modelo occidental del derecho basado en una concepcion antropocéntrica, totalmente ajena a la concepción indígena.

\section{La ley Te Awa Tupua: acta de Reconocimiento del Río Whanganui como sujeto de derechos, de 20 de marzo de 2017.}

El Parlamento de Nueva Zelanda aprobó el 20 de marzo de 2017 la Ley Te Awa Tupua, que declaró persona jurídica al río Whanganui y convirtió en Ley un Acuerdo marco, el Acuerdo de Reclamaciones del Río Whanganui, que resuelve las reivindicaciones históricas de los maoríes. El Acuerdo de Reclamaciones es fruto de muchos años de lucha por parte de la tribu de Whanganui (Whanganui Iwi) por el reconocimiento de infracciones graves por la Corona de sus obligaciones bajo el Tratado de Waitangi. Las quejas se han abordado a través de los procesos del Tribunal de Waitangi, donde una comisión permanente investiga las afirmaciones de los maoríes de que las leyes, políticas, actos u omisiones de la Corona son incompatibles con los principios del Tratado de Waitangi. El Tribunal tiene el poder de recomendar una reparación, que es entonces el tema de negociaciones entre el gobierno de Nueva Zelanda, y iwi y hapū.

El 6 de febrero de 1840 se firmó el Tratado de Waitangi (the Treaty of Waitangi, Te Tiriti o Waitangi) por funcionarios de la Corona británica, en representación de la reina Victoria I, y por jefes maoríes de las tribus de Whanganui, y este Tratado se considera el punto fundacional de Nueva Zelanda como nación. Mediante este Tratado, la Corona garantizó al pueblo Maorí, el ejercicio incondicional de su jefatura sobre sus tierras, pueblos y todos sus tesoros.

La fecha incial del Acuerdo Marco de Reclamaciones del Río Whanganui es el 30 de agosto de 2012, cuando el gobierno de Nueva Zelanda anunció haber alcanzado un acuerdo de principios en las negociaciones con Whanganui Iwi para la solución de su larga reclamación sobre el río Whanganui, donde señala el compromiso para otorgar personalidad jurídica al río Whanganui (Te Awa Tupua) y la 
representación legal de dicha personalidad juídica en la persona física del guardian o tutor, esto es, el guardian de Te Awa Tupua: Te Pou Tupua. Tras la firma del Acuerdo, las negociaciones continuaron y el 26 de marzo de 2014 el Gobierno de Nueva Zelanda anunció que se había firmado una Escritura de Liquidación (Deep of Settlement) por los negociadores, la cual se ratificó el 5 de agosto de 2014. El 2 de mayo de 2016, el Proyecto de Ley 2016 (NZ) de Te Awa Tupua (Acuerdo de Reclamaciones del Río Whanganui) se introdujo en el Parlamento de Nueva Zelanda y, finalmente, se convirtió en Ley en marzo de 2017.

La Escritura de Liquidación (Deep of Settlement) comprende dos documentos: el primero, Ruruku Whakatupua: Te Mana o Te Awa Tupua, relacionado con el reconocimiento del río Whanganui como persona jurídica; y el segundo, Ruruku Whakatupua: Te Mana o Te Iwi o Whanganui, que contiene todos los demás elementos y los documentos del acuerdo.

a) La personalidad jurídica reconocida al Río Whanganui: Te Awa Tupua.

Te Awa Tupua es un conjunto indivisible y vivo, que comprende el río Whanganui desde las montañas hasta el mar, incorporando todos sus elementos físicos y metafísicos. Te Awa Tupua es una personalidad jurídica y tiene todos los derechos, poderes, deberes y responsabilidades de una persona jurídica.

Los derechos, poderes y deberes de Te Awa Tupua -en relación con el río whanganui, o una actividad dentro de su cuenca que afecta al río- deben ser ejercidos o ejecutados, y la responsabilidad debe ser asumida por Te Pou Tupua en nombre de Te Awa Tupua en la forma prevista en esta Ley.

Para brindar asesoramiento y apoyo a Te Pou Tupua en el desempeño de sus funciones, la Ley ha establecido un grupo asesor conocido como Te Karewao; que está integrado por 1 persona designada por los fideicomisarios, y 1 persona designada por las autoridades locales pertinentes; y para el caso de que Te Pou Tupua realice una función en una parte del río, también puede incluir 1 persona designada por el iwi y hapū con intereses en esa parte del río, pero solo con el propósito de brindar asesoramiento y apoyo sobre esa función. Además, Te Pou Tupua puede invitar a otras personas que le asistan o a Te Karewao. 
La Ley ha establecido también un grupo de estrategia para Te Awa Tupua: Te Kōpuka, cuyo propósito es actuar para mejorar la salud y bienestar de Te Awa Tupua. Te Kōpuka está compuesto por un máximo de 17 miembros, representantes de personas y organizaciones con intereses en el río Whanganui, incluidos iwi (seis como máximo), las autoridades locales relevantes, los departamentos de Estado, los usuarios comerciales y recreativos y los grupos ambientalistas. La función principal de Te Kōpuka es desarrollar y aprobar Te Heke Ngahuru (la estrategia del río), monitorear su implementación y revisarlo. El propóssito de Te Heke Ngahuru es proporcionar la colaboración de personas con intereses en el río Whanganui, para abordar y mejorar la salud y el bienestar de Te Awa Tupua, identificar los temas relevantes, proporcionar una estrategia para hacer frente a los problemas y recomendar acciones para su solución. Además tiene otras funciones, como la de proporcionar un foro para la discusión de temas relacionados con la salud y el bienestar de Te Awa Tupua, realizar cualquier función que pueda ser delegada por una autoridad local, y realizar cualquier otra acción que considere apropiada para lograr su propósito y realizar sus funciones. El estado legal de Te Kōpuka es la de un comité conjunto permanente para los fines administrativos del Consejo Regional de Manawatu-Wanganui, el Consejo del Distrito de Ruapehu, el Consejo de Distrito de Stratford, y el Consejo del Distrito de Whanganui; la legislación del gobierno local pertinente no se aplica a Te Kōpuka. Si en cualquier momento el Consejo Regional de Manawatu-Wanganui adopta, bajo cualquier legislación, un proceso de planificación colaborativa para desarrollar una declaración política o plan relacionado con la gestion de agua dulce en la cuenca del río Whanganui, Te Kōpuka será el grupo designado por el consejo para tal proceso.

b) El rostro humano del Río Whanganui, para actuar y hablar por y en nombre de Te Awa Tupua (el tutor o representante legal): Te Pou Tupua.

El propósito de Te Pou Tupua es ser el rostro humano de Te Awa Tupua para actuar y hablar por y en nombre de Te Awa Tupua, para promover y proteger la salud y bienestar de Te Awa Tupua.

La oficina de Te Pou Tupua, el guardián, consta de 2 personas "de alto nivel" designadas por los nominadores según lo establecido en la Ley. Los nominadores deben designar conjuntamente a las 2 personas, teniendo en cuenta la capacidad de 
los nominados para cumplir el propósito y desempeñar las funciones de Te Pou Tupua. Una persona debe ser nominada por el iwi con intereses en el río Whanganui, que con posterioridad al 6 de febrero de 1840 ejerció los derechos y responsabilidades en relación con el uso y la ocupación del río. Y otra persona debe ser nominada en nombre de la Corona.

Según esta Ley, Iwi con intereses en el río Whanganui incluyen: a) el iwi con intereses en el río Whanganui; y b) el hāpa de esos iwi, si esos hāpa tienen intereses en el río Whanganui.

Iwi con intereses en el Río Whanganui incluye el Iwi que actúa en relación con el Río Whanganui River a través de sus organizaciones representativas: Ngā Rauru Kītahi; Ngāti Apa; Ngāti Maniapoto; Ngāti Maru; Ngāti Rereahu; Ngāti Ruanui; Ngāti Tuwharetoa; Whanganui Iwi. Los hapū de esos Iwi, son aquellos que se incluyeron en la lista que Hekenui Whakarake presente en la Comisión Real de Investigación del Lecho del Río Whanganui en 1950: Ngā Paerangi; Ngā Poutama; Ngāti Hau; Ngāti Hāua; Ngāti Kura; Ngāti Pāmoana; Ngāti Patutokotoko/ Ngāti Pketuroa; Ngāti Rangi; Ngāti Ruakā; Ngāti Tuera; Ngāti Tupoho; Ngāti Uenuku. También pueden considerarse grupos de Whanganui Iwi: Hinengakau; Tamaupoko; Tupoho; Tamahaki; Uenuku. La lista no es exhaustiva, refleja solo la hapū que estuvo activa en esos procedimientos y resalta las conexiones entre las hapū que están afiliadas a Whanganui Iwi. Otros grupos no identificados expresamente con los procedimientos, como Ngāti Tamahaki, también se encuentran dentro del significado de Whanganui Iwi para los fines de esta Ley.

c) Los derechos y responsabilidades en relación con el uso y la ocupación del río Whanganui. Las reivindicaciones históricas del Whanganui Iwi (1840).

Los derechos y responsabilidades en relación con el uso y la ocupación del río Whanganuise tienen que ver en el contexto de una visión de unidad e igualdad con la naturaleza del mundo maorí. La visión del mundo maorí también requiere un enfoque intergeneracional: los recursos deben ser protegidos y mejorados para aquellas generaciones que aún no están con nosotros y con respecto a las que han pasado. Los valores con respecto al medio ambiente y las generaciones futuras son recogidos y garantizados de conformidad en el Tratado de Waitangi 1840, documento fundacional de Nueva Zelanda, con una amplia declaración de principios, sobre el 
cual la Corona Británica y los 540 jefes maoríes hicieron un pacto para fundar un Estado y construir un gobierno en Nueva Zelanda.

Las reivindicaciones históricas son todos los reclamos que Whanganui Iwi o una entidad representativa tenían en, antes, o después de la fecha del Acuerdo de Liquidación y que se fundan sobre el sistema de valores indígenas consuetudinarios, reflejado en el dicho "Ko au te awa, ko te awa ko au". En este dicho whanganui "yo soy el río y el río soy yo" subyacen las responsabilidades de iwi (tribus) y hapū (subtribus) de los Whanganui en relación con el cuidado, protección, manejo y uso del río Whanganui.

Desde el primer momento de su colonización por la cultura y el derecho occidental, los indígenas de Nueva Zelanda han defendido su visión ecocéntrica de la vida, y han reivindicado los derechos que le corresponden al Rio Whanganui. La reivindicaciones de Whanganui Iwi empezaron desde el dia que los ingleses hicieron de Nueva Zelanda una colonia británica, el 6 de febrero de 1840. Más de un siglo y medio de negociaciones con la Corona Británica, pidiendo el reconocimiento del río como entidad viva en base a su tradición, tikanga.

Desde la perspectiva de los pueblos indígenas de Nueva Zelanda -Aoteroa, el río es una entidad viviente y forma parte de ellos como un todo completamente orgánico. Los maoríes llegaron a Nueva Zelanda en varias oleadas de viajes en canoa entre 1320 y 1350. Durante siglos, los maoríes han recorrido el río Whanganui en canoa y han luchado por él, porque lo consideran parte de sí mismos; la gente dice: "Ko au te awa. Ko te awa ko au" (Yo soy el río. El río soy yo). La relación maorí (iwi / hapū) con el medio ambiente y los recursos naturales, el agua dulce más específicamente, se basa en su creencia de que los dos son indivisibles.

d) Esta Ley obliga a la Corona neozelandesa

La Ley Te Awa Tupua (Acuerdo de Reclamaciones del Río Whanganui) de 2017 obliga a la Corona, y entró en vigor el día posterior a la fecha de recibir el consentimiento real. El propósito de esta Ley es registrar los agradecimientos y disculpas otorgadas por la Corona a Whanganui Iwi, y resolver las reclamaciones históricas de Whanganui Iwi ya que esas reclamaciones se relacionan con el río Whanganui. 
La ley incluye una compensación del Gobierno a la minoría Whanganui Iwi de 80 millones de dólares neozelandeses, y 30 millones de dólares para mejorar la salud del río Whanganui.

La Corona reconoce que para Whanganui Iwi, el concepto perdurable de Te Awa Tupua, la inseparabilidad de la gente y el río, sustenta las responsabilidades del iwi y hapū de Whanganui en relación con el cuidado, la protección, la gestión y el uso del río Whanganui. La Corona reconoce y respeta la conexión intrínseca entre el iwi y hapū de Whanganui y el río Whanganui. La Corona reconoce la importancia del río Whanganui como fuente de sustento físico y espiritual para iwi y hapū de Whanganui.

La Corona reconoce que el iwi y hapū de Whanganui, durante muchas generaciones desde 1840, han mantenido la posición de que nunca renunciaron voluntaria o conscientemente a sus derechos e intereses en el río Whanganui y han tratado de proteger y mantener su relación especial con el río Whanganui. La Corona reconoce que desde 1840 ha asumido el control y la autoridad sobre el río Whanganui. En particular, la Corona reconoce que promovió e implementó legislación durante el siglo XIX y principios del XX que tenía poco o ningún reconocimiento de los intereses de Whanganui Iwi en el río Whanganui y que no tenía ninguna disposición para la participación de Whanganui Iwi en la gestión del río.

\section{Análisis doctrinal de la Ley Te Awa Tupua desde la perspectiva del nuevo paradigma de la Justicia ecologica.}

El modelo de Justicia ecológica, el principio de sostenibilidad y el concepto de "desarrollo sostenible" caminan juntos, como pone de manifiesto Klaus Bosselmanen en su artículo The Principle of Sustainability: Transforming Law and Governance (2016). El autor define el concepto de Justicia Ecológica en relación al Principio de Sosteniblidad, como una instancia superior capaz de transformar la Ley y la Política. Desde el modelo de Justicia ecológica no basta con cuidar a los seres humanos de hoy ni tampoco a los que vendrán mañana, ya que hoy los procesos vitales que sustentan la vida están en riesgo, por ello, la justicia debe llegar al ámbito extrahumano, esto es, al ámbito del ecosistema, que es el objeto específico de la Justicia ecológica y, precisamente, lo que la diferencia de otros conceptos próximos como la Justicia climática y la Justicia ámbiental. La personalidad jurídica del Río es 
una caracteristica nueva que incluye un enfoque ecocéntrico. De ahí, afirma Bosselmanen, surgen cuestiones jurídicas relevantes, como por ejemplo sobre el contenido de los derechos de un río, en este sentido los ríos pueden tener derechos específicos como por ejemplo "un derecho fundamental del río sería el derecho a fluir", porque la capacidad de fluir (dada suficiente agua) es esencial para la existencia de un río, esta nueva comprensión deriva de la importancia y el propósito del Sistema fluvial en la concepción Maorí.

La idea de sostenibilidad, que predica el modelo de un desarrollo que ya no es igual a crecimiento ilimitado, obliga tanto al Derecho, como a la Política y a la Economía, porque parte de la esfera superior de la Justicia, como señala Melissa K. Scanlan (2017) en su libro Law and Policy for a New Economy Sustainable, Just, and Democratic. La autora insiste reiteradamente en que nuestros derechos humanos tienen responsabilidades individuales y gubernamentales, y que este enfoque es insuficiente para lograr un cambio de paradigma hacia una responsabilidad centrada en la Tierra, en lugar de centrada en el ser humano. La ley debe ir más allá y reconocer nuestros deberes y responsabilidades colectivas e individuales para proteger la naturaleza, tanto por nosotros mismos como por la naturaleza en sí misma.

En la parte de su trabajo que dedica a la Ley de Nueva Zelanda, la autora destaca la visión maorí de la responsabilidad que recoge dicha Ley, que reconoce y refleja la interdependencia entre la cultura indígena de los maoríes y la reponsabilidad de proteger la naturaleza como guardianes, desde un enfoque ecocéntrico. La autora afirma que Nueva Zelanda ha adoptado un método novedoso para defender la responsabilidad humana por la naturaleza: ha reconocido elementos de la naturaleza como persona jurídica y ha designado a un tutor para proteger sus intereses. $Y$ se detiene en dos ejemplos: un río (Te Awa Tupua: Acuerdo de Liquidación del Río Whanganui) y un bosque (Te Urewera: Acuerdo de liquidación de Tuhoe).

El caso de Nueva Zelanda incorpora la cosmovisión de los Maorí como subraya Katie O'Bryan en su libro Indigenous Rights and Water Resource Management: Not Just Another Stakeholder. La autora en la Parte III estudia el caso de Nueva Zelanda, como el primer país que otorga personalidad jurídica a una entidad natural específica. La autora afirma que, aunque la doctrina considera esta iniciativa como un modelo de tutela que sigue la propuesta del Profesor Stone, este enfoque difiere del modelo de 
Stone en el sentido de que el Acta Te Awa Tupua incorpora la cosmovision maorí en la que ven al río como la encarnación de sus antepasados y, por tanto, las personas son inseparables del río: "Ko au te awa, Ko te awa ko au". Se podría concluir, afirma la autora, que si bien el acuerdo donde se otorga personalidad jurídica al río Whanganui es una construcción jurídica occidental, esto es, se basa en conceptos y estructuras legales occidentales, incluso si la version de Stone aplica estas estructuras a entidades naturales que no eran previamente objeto del modelo occidental. Sin embargo, el acuerdo del río Whanganui podría verse como un intento de sincretizar los dos modelos o sistemas diferentes: toma esencialmente un modelo legal occidental, pero le otorga las características del modelo maorí. Y en este sentido, va más allá de la visión inicial de Stone de que un río es una entidad legal que se limita a proteger las características puramente ambientales.

Nuestra época, donde los límites ecológicos de la biosfera han sido superados por el modelo de comportamiento de la humanidad, exige una nueva comprensión de nuestro lugar en el mundo, y nos obliga a repensar las categorías políticas, jurídicas y económica heredadas, como señala Daniel Matthews en su artículo From Global to Anthropocenic Assemblages: Re-trinking Territory, Authority and Rights in the New Climatic. El autor afirma que Gaia es una teoría sobre procesos biogeoquímicos, no una postulación sobre alguna nueva "Diosa" o "Madre Tierra", Pachamama. Para el autor, la hipótesis de Gaia, desarrollada por James Lovelock a principios de la década de 1970 ofrece importantes contribuciones a nuestra comprensión del sistema climático planetario en la era del antropoceno. Lovelock llama "Gaia" y sugiere que la totalidad de los organismos (incluidos, por supuesto, los humanos), las rocas superficiales, los océanos y la atmósfera están unidos en una serie de circuitos de retroalimentación que regulan las condiciones de la superficie en la tierra. Lovelock fue uno de los primeros en argumentar que sin la intervención de organismos vivos, la composición química de la atmósfera, la litosfera y los océanos sería radicalmente diferente.

Sobre el proyecto de aspiración de un constitucionalismo ambiental internacional, el autor se basa en el argumento de Louis Kotzé en su artículo El momento constitucional ambiental global del antropoceno (2015). D. Matthews dice que, a medida que la población urbana planetaria continúa creciendo y las ciudades se convierten en sitios cada vez más importantes de autoridad legal y política, 
debemos entender la ciudad como una forma socio-bio-geoquímica distinta que juega un papel muy importante como sistema terrestre en la configuración de la vida planetaria. Si, como Louis Kotzé ha argumentado, el proyecto aspiracional de un constitucionalismo ambiental internacional carece de un ethos global o planetario suficiente que conecte a los ciudadanos con los regímenes de gobernanza global, es dentro de las formas urbanas contemporáneas que tal ethos bien podría fomentarse. Esto implicaría un alejamiento de un análisis bifurcado que enfatiza lo nacional y lo global, en un esfuerzo por comprender la escena política contemporánea en nuestras formas de población urbana.

En el contexto de los derechos para la naturaleza, afirma Mattehews, el ímpetu detrás de este movimiento se ha reflejado en los recientes desarrollos legales y de jurisprudencia. Particularmente sobre la cuestión en Nueva Zelanda sobre la personalidad jurídica de Te Awa Tupua (río Whanganui) que ha establecido un marco legal por el cual los derechos del río pueden ser representados y defendidos. Para el autor, este enfoque, aunque aparentemente radical, es realmente una continuación de uno de los principios centrales del proyecto moderno que considera la institucionalización de un derecho justiciable como un objetivo fundamental de la acción política.

Finalmente, también es importante analizar el contexto histórico y legal de Nueva Zelanda sobre el que se reclamó la personalidad jurídica al río Whanganui en particular, y no la transferencia de su propiedad de la Corona a los indígenas. Estos asentamientos deben entenderse en el contexto de la historia y la cultura jurídica de Nueva Zelanda, como argumenta Katherine Sanders en su artículo ¿Más allá de la propiedad humana? Propiedad, poder y personalidad jurídica para Naturaleza en Aoearoa, Nueva Zelanda (2018). La autora analiza la concesión de la personalidad jurídica declarada al río Whanganui como parte de un proceso que busca reconocer los errores coloniales y resolver la competencia entre la Corona y los grupos de ascendencia indígena por la tierra y los recursos (la autoridad y la propiedad). También afirma que estos acuerdos de concesión de personalidad juridical pueden considerarse como nuevos marcos para futuras relaciones entre las personas y el medio ambiente. 
Sanders argumenta que la concesión de personalidad jurídica al río Whanganui está profundamente arraigada en la cultura jurídica de Aotearoa-Nueva Zelanda, incluido el tikanga maorí, esto es, los sistemas de valores y leyes consuetudinarios indígenas. En este nivel hay un replanteamiento simbólico de las relaciones entre las personas y el medio ambiente. Pero la autora también argumenta que la concesión de personalidad jurídica en Nueva Zelanda a la tierra (Te Urewera, 2014) y los recursos naturales (2017 Whanganui River) responde a un problema legal distinto. En este otro nivel, la autora se pregunta por qué no se transfirió la propiedad de la tierra y el río, y se adoptó el modelo de no propiedad, ¿Por qué la no propiedad? Para Sanders las razones de la innovación son complejas, estos acuerdos buscan enfocar la toma de decisiones sobre la tierra y el río en torno a un nuevo conjunto de principios y propósitos acordados. En su mayor parte, la Corona descartó la transferencia de tierras de conservación a maoríes como parte de un acuerdo del Tratado; y continúa afirmando la propiedad de los lechos de los ríos navegables en virtud de la Ley de Enmienda de la Ley de Minas de Carbón de 1903 y, aunque argumenta que nadie posee agua según el derecho consuetudinario, reclama la capacidad de asignar derechos al agua dulce bajo la Ley de Gestión de Recursos de 1991.

\section{CONCLUSIONES}

1. Justicia Ecológica, Justicia Ambiental y Justicia Climática

El concepto de Justicia Ambiental tiene su origen en las reivindicaciones ambientales de los años sesenta y setenta. La Justicia Ambiental tiene por objeto los problemas mediambientales y la problematica que el daño ambiental ocasiona a las personas y a todos sus derechos humanos, también los problemas del Derecho y la Jurisprudencia ambiental.

El concepto de Justicia Climática ha ido ganando forma de manera progresiva, tanto mediante los instrumentos internacionales en materia de cambio climático y derechos humanos, como con la Convención Marco de Naciones Unidas sobre Cambio Climático, el Acuerdo de París, los Objetivos de Desarrollo del Milenio y la Agenda 2020-2030. La Justicia Climática tiene por objeto garantizar un clima adecuado, a través de la reducción de las emisiones de gases de efecto invernadero, 
de la transición de las energías fósiles a las energías renovables, y de las medidas de mitigación y adaptación al cambio climático.

Ambos modelos de Justicia se complementan e integran en el concepto más amplio de la Justicia Ecológica que tienen por objeto las interrelaciones del ecosistema donde se incluyen las relaciones de los seres humanos entre sí y con el medio ambiente.

2. Ética ecológica y Justicia ecológica

La fórmula clásicas de la justicia de "dar a cada cual lo suyo" significa, a la luz de una nueva ética ecológica planetaria, un nuevo modelo de distribución que incluye a los elementos del ecosistema, que extiende el ámbito de la ética tradicional. A su vez, la ética ecológica obliga a incorporar una nueva dimensión temporal dentro del concepto Justicia, teniendo como destinatarios a las generaciones futuras.

La nueva ética planetaria impone una nueva racionalidad a la Justicia: ampliar su elenco de destinatarios a todas aquellas especies con las cuales el ser humano comparte el planeta. Bajo esta nueva racionalidad, la Justicia ecológica debe reconocer que cada ser humano, así como los otros elementos del ecosistema, tienen derecho a la conservación, protección y restauración de la salud e integridad de los ecosistemas, en la medida que la naturaleza posee un derecho intrínseco, independiente de su valoración humana, a existir, prosperar y evolucionar.

\section{Desarrollo Sostenible y Justicia ecológica}

El término desarrollo sostenible expresa una nueva medida de la Sostenibilidad que incluye tanto el desarrollo social de las generaciones presentes y futuras, como los límites del ecosistema. La evolución del concepto de Desarrollo, desde el desarrollo humano (Conferencia de Estocolmo de las Naciones Unidas de 1972) hacia el desarrollo sostenible (Cumbre de Río de las Naciones Unidas de 1992), significa el tránsito desde la perspectiva antropocéntrica a la perspectiva ecocéntrica. En un primer momento, el concepto de desarrollo sostenible, que incluye a las generaciones futuras, fue el resultado de los trabajos científicos de la Comisión Mundial del Medio Ambiente que se presentaron en el Informe Brundtland Nuestro Futuro Común de 1986. Cinco años más tarde, en el documento Cuidar la Tierra: Revisión de la Estrategia Mundial para la Conservación de 1991 el concepto de Desarrollo sostenible 
incluye también a los ecosistemas, este documento fue impulsado por el PNUMA, la UICN y el CWWF. El nuevo concepto de desarrollo sostenible, que incluye a las generaciones futuras y a la capacidad ecológica de la Tierra, se consolida en la Cumbre de la Tierra de 1992 como el Principio de Sostenibilidad.

Bajo la priorización de los Principios de Sostenibilidad, la Justicia Ecológica tiene por objeto el mantenimiento de los procesos ecológicos esenciales, sin sobrepasar los límites planetarios.

4. El Estado ecológico de Derecho: derechos humanos ambientales sustantivos y procedimentales o de acceso.

El Estado ecológico de Derecho se entiende como el marco legal de los derechos humanos ambientales sustantivos y los derechos humanos procesales 0 derechos de acceso. El fortalecimiento del Estado de Derecho en materia ambiental constituye la clave para la protección, conservación y restauración de la integridad ambiental (Declaración Mundial de la Unión Internacional para la Conservación de la Naturaleza, firmada en Río de Janeiro 2016).

Los derechos humanos relacionados con el disfrute de un ambiente seguro, limpio, saludable y sostenible están integrados por dos grupos de derechos. Por un lado los derechos procesales o de acceso: derecho de acceso a la información ambiental, participación pública en la toma de decisiones y justicia Ambiental. Y, por otro lado, los derechos sustantivos, que incluyen: derecho a la vida, integridad personal, salud, agua potable y saneamiento, alimentos, vivienda, propiedad, paz, derechos de los pueblos indígenas y comunidades locales, derechos de las personas en casos de catástrofes, derechos de personas desplazadas ambientalmente y los derechos de los defensores de los derechos humanos.

Mediante la aplicación del enfoque integral de los derechos humanos ambientales con el derecho al medio ambiente, sería posible llevar a cabo la ecologización de los derechos humanos. Este enfoque integral de los derechos humanos ambientales se refiere a la interrelación e interdependencia existente entre la tríada de derechos humanos ambientales procedimentales y su aplicación de forma equilibrada, para hacer efectivos los derechos ambientales sustantivos, y el disfrute de un ambiente seguro, limpio, saludable y sostenible. 
5. La ecologización de los derechos humanos: los derechos bioculturales y los derechos de la naturaleza.

La ecologización de los derechos humanos, los derechos ecológicos, se refieren a una vision más amplia de los derechos de las personas que permite, tanto el reconocimiento de los derechos socio-ecológicos por ejemplo el derecho humano al agua potable, o el derecho a la soberanía alimentaria, como el reconocimiento de los derechos de las comunidades étnicas en relación con su entorno natural y cultural, lo que se ha denominado, derechos bioculturales; y permite también el reconocimiento de los derechos de la naturaleza. El elemento central de este enfoque es la existencia de una vinculación intrínseca entre naturaleza y cultura, entre el ecosistema y la especie humana.

\section{Estado ecológico de Derecho y Justicia ecológica}

Para alcanzar los objetivos de la Justicia Ecológica, el Estado ecológico de Derecho debe garantizar los derechos humanos relacionados con el disfrute de un medio ambiente seguro, limpio, saludable y sostenible (el derecho al medio ambiente y los derechos humanos ambientales), garantizando, al mismo tiempo, el mantenimiento de los procesos ecológicos esenciales sin exceder los límites planetarios.

El Estado ecológico de Derecho tiene por objeto las nuevas relaciones ecosistémicas de las que forma parte el ser humano. El objetivo del Estado ecológico de Derecho es lograr la justicia ecológica entre Estados, y la solidaridad entre generaciones y entre especies. En definitiva, la racionalidad que presupone el Estado de Derecho ya no es antropocéntrica sino ecocéntrica. El Estado ecológico de Derecho pretende dar respuesta a los problemas ecológicos, sociales y económicos de la era geológica del Antropoceno, donde la eficiencia económica y la justicia social solo son posibles dentro de los límites de los sistemas ecológicos locales, regionales y planetarios.

7. Aportaciones del constitucionalismo andino al constitucionalismo occidental: la "Constitución ecológica".

Algunos sistemas jurídicos empiezan a reconocer a nivel constitucional, legal y jurisprudencial, los denominados derechos de la naturaleza, otorgándole 
personalidad jurídica propia a la naturaleza, a los diversos ecosistemas. En este sentido, la Constitución de Colombia de 1991, permite esta consideración a partir del reconocimiento de la concepción ecocéntrica como ha puesto de manifiesto la Sentencia objeto de estudio; la Constitución de Ecuador del 2008, reconoce de forma expresa a la naturaleza como sujeto de derechos, admitiendo su valor intrínseco independientemente de su utilidad; y la Constitución de Bolivia de 2009 reconoce a la naturaleza como sujeto de derechos. La clave de las contribuciones de concepción andina e indígena es el nuevo concepto de la relación entre el ser humano y el ecosistema.

Por otro lado, el desarrollo cultural y espiritual de occidente no ha integrado en medida fundamental a la naturaleza. Se ha considerado a la naturaleza como un recurso infinito que pertenece al ser humano para su explotación sin límites. La superación de tales planteamientos erróneos, plantea ahora la necesidad de una síntesis que trascienda las diferencias entre naturaleza y cultura. En esta tarea de repensar el conocimiento y, en especial el Derecho, como exigencia de la crisis climática y ecológica que sufrimos, puede servir de ejemplo la visión ecocéntrica defendida desde el constitucionalismo andino y la visión indígena.

8. Desafíos de la Justicia Ecológica en el siglo XXI

En la era del Antropoceno, el nuevo modelo de Justicia enfrenta una serie de retos y desafíos relacionados con su objetivo de mantener los procesos fundamentales que sustentan la vida en la Tierra, dentro de los límites planetarios. La Justicia Ecológica debe encontrar el justo equilibrio entre integridad ecológica, la eficiencia económica y la equidad social, tal y como lo exige el nuevo modelo de desarrollo sostenible, que debe ser reinterpretado a la luz de los principios de sostenibilidad ecológica y resiliencia. 


\section{BIBLIOGRAFIA}

Baxi, U.,"Toward a climate change justice theory?", en Journal of Human Rights and the Environment, Vol. 7, n¹, 2016.

Barry, B.,"Circumstances of Justice and Future Generations", en "Obligations to Future Generations", Richard I. Sikora \& Brian M. Barry (eds), White Horse Press, Cambridge, 1978.

Birnbacher, D. (editor),“Ökologie und Ethik”, Philipp Reclam jun., Stuttgart, 1980.

Bosselmanen K., "The Principle of Sustainability: Transforming law and governance", Routledge, London, 2016.

Carson, R.,"Silent Spring”, Houghton Mifflin Harcourt, United States, 1962.

Darwin, C., "The Descent of Man”, Murray, London, 1874.

Dobson, A., "Ciudadanía ecológica", en Isegoría Revista de Filosofía Moral y Política $n^{\circ} 32,2005$.

Fraser, N.,"Redefiniendo el concepto de justicia en un mundo globalizado”, en Análes de la Cátedra Francisco Suárez n³9, 2005.

Hison, C.,"Republican ecological citizenship in the 2015 Papal Encyclical on the environment and climate change", en Critical Review of International Social and Political Philosophy, Volume 21, Issue 6, 2018.

Jonas, H.,"El principio de responsabilidad. Ensayo de una ètica para la civilización tecnológica", Herder, Barcelona, 1995.

Leopold, A., "A Sand Country Almanac and Sketches Here and There", Oxford University Press, New York, 1949.

Lovelock, J., "Gaia, una vision de la vida sobre la Tierra", Hermann Blume, Barcelona, 1983.

Margalef, R.,“Ecología”, Omega, Barcelona, 1974.

Marshall, T., "Prisioners of Geography: Ten Maps that tell you Everything you need to Know about Global Politics”, Elliott \&Thomson Limited, London, 2016. 
Matthews, D., "From Gobal to Anthropocenic Assemblages: Re-thinking Territory, Authority and Rights in the new Climatic Regime”, Modern Law Review, Volume 82, Issue 4, 2019.

Mount, N., "Can a river have legal rights? I visited the jungles of Colombia to find out", The Conversation, United Kingdon, 2017.

O’Bryan, K., "Indigenous Rights and Water Resource Management: Not Just Another Stakeholder", Routledge, London, 2018.

Peña Gascón, M., "Justicia ecológica en el siglo XXI", en Revista de Derecho Ambiental n57, Thomson Reuters, Argentina, 2019.

Peña Gascón, M., “Ecologización de los Derechos Humanos. Comentarios a la sentencia constitucional", en Derechoaldía.com, 2018

Quirico, Q. and Bounghar, M., "Climate Change and Human Rights", Routledge, London, 2016.

Royal, S., "Manifest pour une Justice Climatique”, Editions Plon, París, 2017.

Salazar, E., "El acceso a la justicia ambiental a partir del Convenio de Aarhus", Thomson Reuters Aranzadi, España, 2019.

Scanlan, M. K., "Law and Policy for a New Economy Sustainable, Just, and Democratic", Edward Elgar Publishing, United Kingdom, 2017.

Shiva, V.,"Manifiesto por una Democracia de la Tierra: Justicia, Sostenibilidad y Paz", Paidós, Barcelona, 2006.

Spaemann, R., "Technische Eingriffe in die Natura als Problem der politischen Ethik", en "Ökologie und Ethik", Dieter Birnbacher(editor), Philipp Reclam jun., Stuttgart, 1980.

Stone, C., "Should Trees Have Standing? Toward Legal Rights for Natural Objets", en Southern California Law Review ,n45, 1972.

Tribe, L. H.,"Was spricht gegen Plastikbäume?”, en “Ökologie und Ethik”, Dieter Birnbacher(editor), Philipp Reclam jun., Stuttgart, 1980. 
Vicente, T., "El nuevo paradigma de la Justicia ecológica y su desarrollo ético-jurídico" In: "Justicia ecológica en la era del Antropoceno", Teresa Vicente (editora) Trotta, Madrid, 2016.

Vicente, T. y Ramirez, L., “Justicia y Ecología: presupuestos científicos para el desarrollo de una Justicia ecológica”, Nau Llibres, Valencia, 1997.

Wilson, E. O., "Half-Earth: Our Planet's Fight for Life”, Liveright, New York, 2016.

Wedy, G., “Litigios Climáticos”, Editoria Juspodivm, Brasil, 2019.

Zaffaroni, R.,“La Pachamama y el humano”, Editorial Colihue, Argentina, 2012. 